\title{
Acquired reactive perforating collagenosis
}

\author{
Alexander Kreuter MD, Thilo Gambichler MD
}

Previously published at www.cmaj.ca

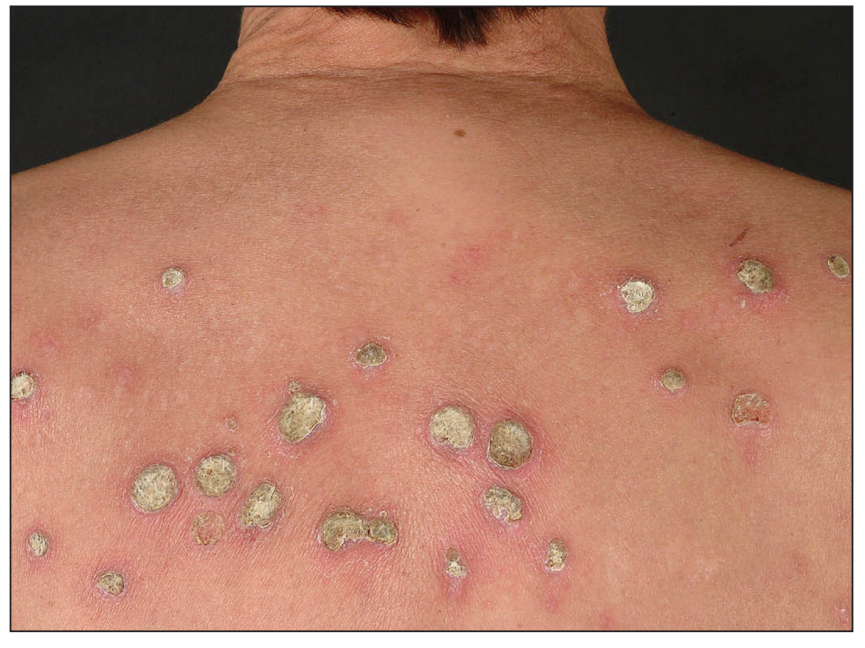

Figure 1: Numerous erythematous plaques with central keratotic plugs on the upper back of a 58 -year-old woman. 58-year-old woman with diabetes mellitus and chronic kidney disease who was receiving hemodialysis presented with a five-month history of pruritic skin lesions on her upper back. Examination showed numerous erythematous papules and plaques with central keratotic plugs (Figure 1). Histopathologic evaluation of a representative lesion showed transepidermal elimination of necrotic collagen bundles into a cup-shaped epidermal depression (Figure 2). Acquired reactive perforating collagenosis was diagnosed. All necrotic debris was removed by curettage. Treatment was started with betamethasone valerate cream $0.1 \%$ twice daily for four weeks and narrowband ultraviolet-B phototherapy five times weekly for two weeks, then three times weekly for four weeks. Nearly all the skin lesions cleared with treatment.

Acquired reactive perforating collagenosis is an uncommon condition in which altered collagen bundles are eliminated 6 through the epidermis. ${ }^{1,2}$ The cause is unknown, although it may be a cutaneous response to superficial trauma caused by intense scratching. People with microvasculopathy seem to be

From the Department of Dermatology, Ruhr University, Bochum, Germany CMAJ 2010. DOI:10.1503/cmaj.091185

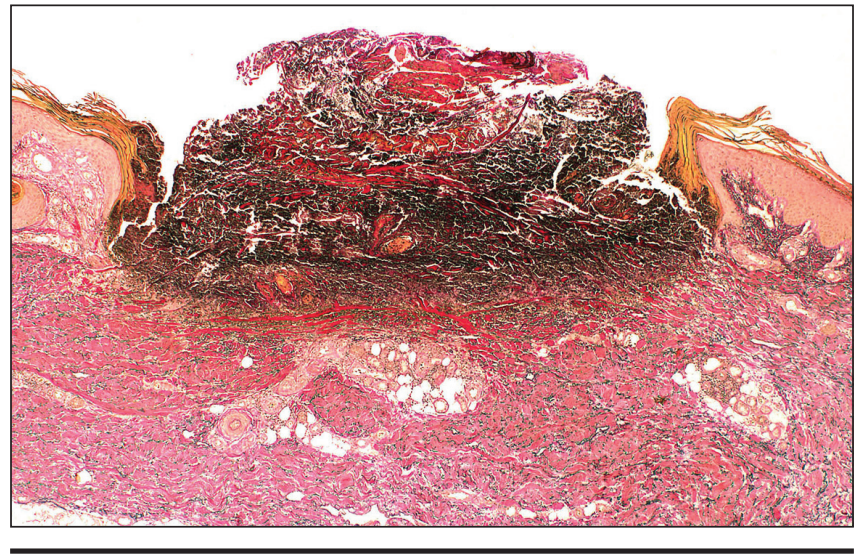

Figure 2: Histopathologic image of one of the lesions (Elastica van Gieson stain, original magnification $\times 40$ ), showing elimination of collagen bundles through the dermis into the epidermis. The central crusted keratotic plug contains keratin, cellular debris and collagen fibres.

highly susceptible to the disease. Associations have been made between acquired reactive perforating collagenosis and diabetes mellitus with chronic renal failure, and it has been reported in up to $11 \%$ of patients receiving dialysis. ${ }^{3}$ It has also been observed in patients with lymphoma, AIDS, hyperparathyroidism, liver dysfunction and atopic dermatitis. ${ }^{2}$

Many treatments have been reported, including topical and systemic corticosteroids, retinoids, doxycycline, phototherapy and allopurinol. ${ }^{4}$ There is little evidence supporting these treatments, and no controlled studies or treatment guidelines are available. In most instances, pruritus lessens with clearing of the skin lesions.

This paper has been peer reviewed.

Competing interests: None declared.

\section{REFERENCES}

1. Rapini RP, Herbert AA, Drucker CR. Acquired perforating dermatosis. Evidence for combined transepidermal elimination of both collagen and elastic fibers. Arch Dermatol 1989;125:1074-8.

2. Faver IR, Daoud MS, Su WP. Acquired reactive perforating collagenosis. Report of six cases and review of the literature. J Am Acad Dermatol 1994;30:575-80.

3. Morton CA, Henderson IS, Jones MC, et al. Acquired perforating dermatosis in a British dialysis population. Br J Dermatol 1996;135:671-7.

4. Hoque SR, Ameen M, Holden CA. Acquired reactive perforating collagenosis: four patients with a giant variant treated with allopurinol. Br J Dermatol 2006;154:759-62. 